\title{
A noção de inconsciente nos primeiros textos de Freud: do cognitivo ao reino das sombras
}

\section{The notions of unconscious on the first Freudian texts: from the cognitive to the romantic}

\section{Las nociones de lo inconsciente en los primeros escritos de Freud: de la cognitiva al romántico}

\author{
Henrique Fróes* \\ Universidade de Brasília - UnB, Brasília, Distrito Federal, Brasil \\ Terezinha de Camargo Viana** \\ Universidade de Brasília - UnB, Brasília, Distrito Federal, Brasil
}

\begin{abstract}
RESUMO
O artigo investiga o uso da noção de inconsciente nos primeiros textos de Freud, que compreendem os anos de 1888-1893, pertencentes ao período denominado pré-psicanalítico. A partir daí, estabelece os diversos sentidos que a noção de inconsciente assume, relacionando-os com os diversos autores e tradições que serviram de fonte para o pensamento freudiano, ou que o antecederam. Identificam-se três diferentes modelos de concepção do inconsciente que surgem como referência para Freud: o do inconsciente cognitivo, o do inconsciente resultante da divisão da consciência e o do inconsciente romântico, que vão se desdobrando concomitantemente à ênfase dada à abordagem psicológica dos fenômenos patológicos da histeria.

Palavras-chave: Inconsciente, Freud, História, psicologia, século XIX.
\end{abstract}

\section{ABSTRACT}

This article investigates the notions of the unconscious that emerges from Freud's first texts - which, published between 1888-1893, belongs to the pre-psychoanalytic era. To this end, it establishes the different meanings that the notion of unconscious assumes, relating them with the diverse authors and traditions, which served as a source for the Freudians thought or which preceded him. Three different models of unconscious are identified: the cognitive one, the one resulting from the division of consciousness and the romantic one, all of which simultaneously to the emphasis given to the psychological approach of the pathological phenomena of hysteria.

Key words: Unconscious, Freud, History, psychology, XIX century.

\section{RESUMEN}

El presente trabajo investiga el uso del inconsciente en los primeros escritos de Freud, entre los años de 1888 y 1893, perteneciente al período conocido como pre-psicoanalítico. Desde allí, establece los diferentes sentidos que asume la noción de inconsciente, relacionándolos con los diversos autores y tradiciones que sirvieron de fuente para el pensamiento de Freud, o antes de 
él. Identifica tres modelos distintos de concepción de lo inconsciente que aparecen como referencia para Freud: del inconsciente cognitivo, del inconsciente resultante de la disociación de la conciencia y del inconsciente romántico, que se van desarrollando simultáneamente a la énfasis en el enfoque psicológico de los fenómenos patológicos de la histeria.

Palabras clave: Inconsciente, Freud, Historia, psicología, siglo XIX.

\section{Introdução}

Na longa história do inconsciente, Freud surge como um marco que provoca uma ruptura e inicia uma nova era. A criação de uma disciplina que toma para si o inconsciente como objeto de investigação, como costumeiramente é caracterizada a psicanálise, levou a uma falsa impressão de que o próprio conceito era obra de Freud. Em uma versão algo mítica, popularizada nos livros introdutórios e nas salas de aula, Freud, isolado da comunidade médica e científica, empreende uma heroica autoanálise e dela emerge com a descoberta revolucionária do inconsciente.

Nada mais equivocado em termos históricos. No século anterior à Interpretação dos sonhos, de 1900, e com origens ainda mais recuadas no tempo, já havia se desenvolvido no pensamento ocidental uma série de discursos sobre o inconsciente, seja no campo da filosofia quanto no das artes, seja no campo da medicina quanto no da psicologia. É possível dizer que o inconsciente, como um objeto científico, já havia sido construído. Ao mesmo tempo em que pode ser encarada como apenas mais um discurso sobre esse objeto, a psicanálise também pode ser vista como fundante de um outro inconsciente, graças ao novo olhar lançado sobre ele. Aqui, as opiniões divergem: Ellenberger (1970), por exemplo, busca caracterizar o pensamento freudiano mais como uma continuação do que uma ruptura com o que ele denominou a primeira psiquiatria dinâmica. Já para Lacan (2008), o inconsciente proposto por Freud não guarda relação com 0 que foi dito sobre esse objeto anteriormente.

Para tentar estabelecer em que medida o pensamento freudiano apropria-se dos discursos sobre o inconsciente que o antecederam e também promove rupturas com essa tradição, este trabalho busca identificar nos primeiros textos de Freud a existência de uma noção de inconsciente e situá-la em suas aproximações com os outros discursos que também o tomam como objeto. Assim, é possível acompanhar os modos como o pensamento freudiano vai se relacionando com a tradição e os movimentos que faz em direção a uma conceituação própria de inconsciente.

Para isso, foram analisados e selecionados textos de Freud compreendidos no período de 1888 a 1893 que façam referências diretas ou indiretas ao modo como Freud entende e se apropria da 
ideia de inconsciente para, a partir daí, estabelecer as relações com os diversos discursos existentes sobre o inconsciente. O período escolhido, tradicionalmente denominado pré-psicanalítico, é anterior àquele em que Freud vai desenvolver o conceito de defesa e estabelecer as bases para um novo entendimento sobre 0 inconsciente (Fróes \& Viana, 2013).

Este trabalho busca contribuir para o campo da epistemologia psicanalítica, a partir de uma pesquisa de cunho histórico que ajude a identificar algumas das fontes utilizadas por Freud no desenvolvimento de um conceito metapsicológico fundamental, cujo impacto no pensamento psicológico e das ciências humanas como um todo é indiscutível. O conhecimento das outras noções de inconsciente anteriores a Freud ajuda a iluminar como se deu a construção do conceito de inconsciente psicanalítico, determinando os pontos de convergência e de ruptura com outros discursos sobre esse mesmo objeto, possibilitando, assim, uma compreensão mais clara de seu conteúdo.

\section{Inconsciente Cognitivo}

Dos textos reunidos no Volume I das Obras Completas, o primeiro que merece destaque no âmbito desse estudo é o verbete Histeria (2006b), escrito para a enciclopédia de Villaret e publicado sem a assinatura de Freud, mas sobre o qual não pairam dúvidas de sua autoria. Nele, Freud deixa patente seu entusiasmo pelo pensamento de Charcot, que domina praticamente todos os aspectos abordados no texto. A concepção etiológica da doença expressa no verbete corresponde quase exatamente àquela defendida por Charcot, em que o fator hereditário é preponderante, tornando os outros (traumas, intoxicações, emoções) secundários. Estes, chamados agentes provocadores, possuem importância meramente prática ao ativarem a disposição histérica, desencadeando a forma aguda da doença (Andersson, 2000).

Em um ponto, entretanto, Freud irá discordar de seu mentor. É quando ele descarta a hipótese anatomofisiológica formulada por Charcot de que determinados sintomas histéricos seriam causados por uma lesão dinâmica que afetaria os mesmos locais de uma lesão orgânica provocadora de efeitos similares. O texto da enciclopédia é enfático quanto a esse ponto:

A histeria é uma neurose no mais estrito sentido da palavra -quer dizer, não só não foram achadas nessa doença alterações perceptíveis do sistema nervoso, como também não se espera que qualquer aperfeiçoamento das técnicas de 
anatomia venha a revelar alguma dessas alterações (Freud, 2006b, p. 77)

Andersson (2000) afirma que essa posição de Freud expressa mais sua diferenciação em relação a Meynert, seu ex-professor, do que propriamente a Charcot, que, progressivamente, vai abandonando a visão anatomopatológica ao qual o primeiro se manteve aferrado. Freud estaria sob a influência da eletrofisiologia e das novas descobertas sobre as funções do sistema nervoso, cujos desdobramentos podem ser exemplificados pelo quadro de síndrome neurastênica proposto por Beard, objeto de amplas discussões na época. É nesse contexto que Freud considera os distúrbios psíquicos que ocorrem no quadro histérico, tais como inibições da vontade e desvios nas associações de ideias, como "alterações na distribuição normal, no sistema nervoso, das quantidades estáveis de excitação" (Freud, 2006b, p. 85).

Ao referir-se ao fato de que nem todos os histéricos apresentam tais sintomas psíquicos, Freud usa pela primeira vez no texto o termo inconsciente. Escreve ele:

Os sintomas psíquicos têm sua significação dentro do quadro total da histeria, mas não são mais constantes do que os diferentes sintomas físicos, os estigmas. Por outro lado, as modificações psíquicas, que devem ser assinaladas como o fundamento do estado histérico, ocorrem inteiramente na esfera da atividade cerebral inconsciente, automática. Talvez ainda se possa acentuar que na histeria (como em todas as neuroses) aumenta a influência dos processos psíquicos sobre os processos físicos do organismo, e que os pacientes histéricos funcionam com um excesso de excitação no sistema nervoso excesso que se manifesta ora como inibidor, ora como irritante, deslocando-se com grande mobilidade dentro do sistema nervoso (Freud, 2006b, p. 86).

Nesse trecho, Freud busca explicar o fato de que, apesar da histeria implicar necessariamente em modificações psíquicas, nem sempre elas surgem aos olhos do médico ou mesmo do paciente. Tais mudanças se dão em uma esfera, a da atividade cerebral inconsciente, cuja influência pode, muitas vezes, se dar apenas sobre os sintomas físicos. Em outro trecho, Freud volta a essa questão. Ao discorrer sobre o tratamento da histeria, ele especifica o modo de ação sobre os sintomas isolados da doença: "o tratamento direto consiste na remoção das fontes psíquicas que estimulam os sintomas histéricos, e isto se torna compreensível se buscarmos as causas da histeria na vida ideativa inconsciente" (Freud, 2006b, p. 93). 
A própria linguagem utilizada por Freud nos trechos citados revela a duplicidade do lugar que ocupa no momento: "atividade cerebral inconsciente" remete a uma concepção puramente neurológica, enquanto "vida ideativa inconsciente" já se aproxima de uma visão mais próxima ao campo da psicologia. Essa dualidade é a mesma encontrada no pensamento de Charcot, como pode-se notar em seus comentários ao caso de um paciente chamado Joseph Le Logeais, que é acometido de uma paralisia após ser atropelado por uma viatura. $O$ jovem recebe alta do acidente, mas, pouco tempo depois, entra em coma e, ao acordar, está com as duas pernas sem movimento. Para Logeais, o carro teria passado sobre suas pernas, imagem que the volta em sonhos, apesar de não ser verdadeira. Em sua abordagem do caso, Charcot dirá que esse homem inventou inconscientemente esse detalhe do acidente e que, devido ao coma, haveria se dado uma condição de dissociação do eu, análoga ao do sonambulismo, que permitiria que essa ideia fosse concretizada, em um processo denominado de autossugestão.

Pode-se comparar o processo de que se trata com uma espécie de ação reflexa no qual o centro do arco diastáltico é representado pelas regiões do córtex cinzento onde se operam fisiologicamente os fenômenos psíquicos relativos aos movimentos voluntários dos membros. Em razão da dissociação fácil da unidade mental, do eu, em casos deste gênero, estes centros podem ser colocados em jogo, sem que as outras regiões do órgão psíquico sejam advertidas e chamadas a participar do processo (Charcot, citado em Cazeto, 2001, p.289)

Como ressalta Cazeto (2001), Charcot desenha nesse período um inconsciente fundamentalmente neurológico. Essa concepção é muito similar à utilizada por Freud no texto em questão. Em outro escrito do mesmo ano, o prefácio à tradução do livro de Bernheim intitulado Sobre a sugestão (Freud, 2006c), o caráter fisiológico dos processos inconscientes ressurge no contexto das diferenças entre Charcot e Bernheim sobre a hipnose. O texto estabelece a posição deste último, representante da chamada Escola de Nancy, que considera como psíquicas todas as manifestações hipnóticas, sendo essas frutos da sugestão. A posição contrária é aquela defendida por Freud: a de que pelo menos alguns dos mecanismos dos fenômenos provocados pela hipnose são baseados em modificações fisiológicas. Tais modificações são entendidas como "deslocamentos da excitabilidade no sistema nervoso, que ocorrem sem a participação das partes do mesmo que operam com a consciência" (Freud, 2006c, p. 113).

A visão psicofisiológica de Freud que subjaz a esses escritos é mais claramente delineada no verbete sobre o cérebro produzido para a 
mesma enciclopédia de Villaret. Nela, Freud postula uma ligação entre as modificações materiais que ocorrem no órgão e aquelas da consciência, ressaltando o desconhecimento sobre tal mecanismo. Não há, na concepção de Freud, uma relação inequívoca entre as modificações nas duas esferas: "às vezes, uma certa modificação material é acompanhada por 'eventos imateriais' correspondentes, ou seja, por fenômenos psíquicos que 'ultrapassam o limiar da consciência'; outras vezes, ao invés, concomitantemente à modificação material, não sobrevém qualquer modificação na consciência" (Freud, citado em Andersson, 2000, p. 104). Para ele, uma modificação material é acompanhada de um fenômeno consciente quando ocorre uma direção arbitrária da atenção ou mesmo uma superação voluntária do limiar de consciência. Ele considera, no entanto, que muitos aspectos dos processos psíquicos, ou todos eles, podem permanecer sob esse limiar, o que não implicaria no fato de qualquer elemento do processo material ter que ser representado de forma diferente por causa disso.

Para Andersson (2000), as descrições psicológicas e fisiológicas empregadas por Freud nessa época estavam relacionadas aos problemas da atenção e da consciência. Nesse sentido, o termo inconsciente estaria sendo usado para definir processos cerebrais que, por não serem objetos da atenção, não chegariam à consciência. As referências de Freud nesse terreno são o esquema do arco reflexo e os processos associativos. O uso do termo automático como similar ao de inconsciente ressalta o caráter mecânico desses processos cerebrais.

Freud insere-se aqui em uma tradição filosófico-histórica denominada por Gödde (2010) de inconsciente cognitivo. Ela tem sua origem com Leibniz e sua noção de "pequenas percepções" (petites perceptions) que, isoladas, são fracas demais para serem notadas, mas que, combinadas com outras, possuem a habilidade de adentrar a consciência. O famoso exemplo utilizado pelo filósofo alemão para ilustrar esse fenômeno é o da audição do barulho do mar: o som de cada onda individualmente não é percebido na consciência, e sim a da soma delas. No entanto, para Leibniz, cada uma produz uma petite perception sem a qual não se ouviria o todo. A partir dessas noções, o filósofo e teórico da psicologia Herbart vai desenvolver uma visão dinâmica em que representações e percepções lutam entre si para ultrapassarem o limiar da consciência: aquelas reprimidas pelas mais fortes procuram associar-se com outras para, assim, transpassarem a linha divisória (Ellenberger, 1970). Fechner e Helmholtz são outros nomes pertencentes a essa tradição.

A suposta influência de Herbart sobre o pensamento freudiano é alvo de constantes polêmicas (Jones, 1959; Leader, 2010). Andersson (2000) aponta que, nos textos de 1888, é possível detectar pontos de contato com as teorias herbartianas, mas que eles não 
necessariamente indicam uma relação direta. De qualquer forma, tais pontos revelam a inserção de Freud em um tipo de discurso sobre o inconsciente já estabelecido.

(...) não encontramos entre os artigos de Freud daquele ano qualquer referência a processos psicológicos diferentes daqueles compatíveis com a tradição associacionista genérica. Ele usava, no entanto, alguns termos e pontos de vista similares àqueles da psicologia herbartiana. A atenção (aufmerksamkeit) era de fato mencionada como o processo psíquico por meio do qual as ideias com potencial de se tornarem conscientes podiam chegar à consciência. Nesses artigos encontramos também a utilização do conceito de 'limiar da consciência'. Mas é preciso levar em conta que esses termos eram usados muito comumente naquele tempo, seja pelos seguidores do herbartismo, seja entre outros psicólogos que operavam com independência em relação àquela tradição (Andersson, 2000, p. 110).

No verbete para a enciclopédia de Villaret, uma passagem parece destoar em relação ao emprego do termo inconsciente. Ao abordar a questão da evolução da histeria, o texto discorre sobre a capacidade de um órgão, mesmo tendo sido acometido por um distúrbio por vários anos, retomar à sua funcionalidade sem sequelas. Por outro lado, escreve Freud, "a evolução dos distúrbios histéricos muitas vezes exige uma espécie de incubação, ou melhor, um período de latência, durante o qual a causa desencadeante continua atuando no inconsciente" (Freud, 2006b, p. 89). Garcia-Roza (2001) destaca, nesse trecho, o uso do termo na forma substantiva, apontando para a existência não só de processos cerebrais inconscientes, mas também para um lugar psíquico específico.

Não há, em textos desse período, outro uso do termo inconsciente dessa forma. Strachey (2006) aponta que a primeira utilização do termo no sentido psicanalítico será feita por Breuer durante o relato do caso Anna O., em 1895. Uma nota de rodapé à tradução do livro de Bernheim parece indicar que Freud não concebia uma localização específica onde se dariam os processos inconscientes. Diz a nota: "parece-me injustificável e desnecessário supor que uma ação mude de localização no sistema nervoso, se ela foi iniciada conscientemente e, depois, inconscientemente. Ao contrário, é provável que a região cerebral em questão possa operar com uma quantidade variável de atenção (ou consciência)" (Freud, 2006c, p. 120). É a atenção que vai determinar o caráter consciente ou inconsciente de uma ação, não importando a sua localização dentro do sistema nervoso, já que ainda parece não haver sequer esboço de um aparelho psíquico que comportasse um inconsciente. $O$ uso do termo inconsciente tem, 
nesse momento do pensamento freudiano, apenas um significado descritivo. Como sintetiza Andersson: "Em 1888-1889, o termo 'inconsciente' era sinônimo de 'não-psíquico', sendo usado, primordialmente, de uma maneira figurativa, referindo-se a processos que não tinham possibilidade de se tornarem conscientes, e que eram descritos em sua maior parte como processos fisiológicos" (Andersson, 2000, p. 158).

Nos textos desse período (1888-1891), Freud já faz referência às descobertas de Breuer no campo do tratamento da histeria, mas de uma forma limitada. Ao contrário do que será desenvolvido posteriormente como o método catártico, o que Freud propõe é que o uso da sugestão após a rememoração da ocasião que originou 0 sintoma torna-se mais efetivo. A ideia de ab-reagir as lembranças traumáticas somente será elaborada no período imediatamente posterior. Aqui, Freud demonstra ainda estar sob a influência da obra de Bernheim, e utilizava a sugestão para eliminar ou apagar a memória dos eventos que alimentariam os distúrbios histéricos.

\section{Inconsciente como Resultado da Divisão da Consciência}

Um outro tipo de inconsciente vai surgir no pensamento freudiano com a noção de dissociação da consciência, que aparece tanto na Comunicação Preliminar - Sobre o mecanismo psíquico dos fenômenos histéricos (2006a), escrita em parceria com Breuer, quanto nos esboços preparatórios a esse texto. Uma segunda consciência surge como resultado desse processo, que seria a característica mesma da histeria. A própria nomeação desse outro lugar como consciência segunda indica essa relação de subordinação. Breuer e Freud (2006a) vão descrever o processo de constituição desse inconsciente, que é secundário e adquirido. Existe uma tendência na histeria à dissociação da consciência, o que provoca o surgimento de estados anormais (chamado de hipnóides). Quando um neurótico encontra-se em um desses estados, podem surgir representações que ficarão impossibilitadas de se inserirem no conteúdo da consciência. Essas representações isoladas (sempre muito intensas) podem associar-se entre si e, assim, formarem uma seconde conscience organizada. Esse processo, no entanto, não é exclusivo dos histéricos e pode ocorrer em pessoas normais que forem vítimas de um trauma psíquico - uma experiência (dor, susto, vergonha, etc.) - que desperte afetos aflitivos. É quando essa segunda consciência adquire controle sobre a existência do doente que os ataques histéricos ocorrem.

Para ser traumática, não basta uma experiência ser apenas aflitiva: ela deve também ter sido impedida de ser ab-reagida, ou seja, de ter sua carga de afeto devidamente despendida por meio de reação ou 
elaboração. No caso dos não histéricos, isso se dá quando há uma impossibilidade de reação ou quando a pessoa deseja esquecer 0 evento e recalca a sua lembrança. A psicoterapia proposta por Breuer e Freud a partir desse modelo consiste em, por meio da hipnose, permitir que as lembranças dissociadas reapareçam de forma tal que o afeto a elas ligado seja ab-reagido. Tal processo ocorre quando o paciente consegue descrever todos os detalhes do evento traumático e traduzir o afeto correspondente em palavras.

Como ressalta Andersson (2000), o mecanismo da ab-reação tinha como pressuposto um modelo fisiológico não explicitado no texto, cujas ideias principais eram a de um sistema nervoso empenhado em manter um equilíbrio energético e que, por meio da descarga, livrava-se dos excessos de excitação. Os distúrbios histéricos surgem quando a descarga não é efetuada. O fato de Breuer e Freud terem optado por abordar sua teoria em bases psicológicas estaria ligado não só a uma incapacidade de expressar essas ideias em termos fisiológicos devido às limitações desse campo, como também à adesão de uma tendência entre seus pares contemporâneos no mesmo sentido de privilegiar a abordagem clínica e psicológica.

Essa tendência surge como desdobramento das investigações de Charcot sobre a histeria traumática. Em trecho transcrito anteriormente, ele refere-se a uma tendência à dissociação da unidade mental nesses casos de histeria. Nos casos clínicos investigados na Salpêtrière, começam a aparecer os fenômenos da dupla personalidade (Cazeto, 2001). Entre eles, a de uma paciente chamada Emma Dutemple, que sofre de um estranho caso de amnésia: após receber a notícia (falsa) da morte do marido, tem uma crise nervosa de três dias e desenvolve uma amnésia de todos os fatos recentes posteriores ao dia do anúncio traumático. No entanto, ao ser submetida à hipnose, Emma mostra-se capaz de responder a todas as perguntas referentes aos acontecimentos dos quais nada recorda em vigília. Nas explicações sobre o caso, Charcot vai postular a existência de um eu inconsciente.

(...) todas estas lembranças assim registradas inconscientemente revivem na hipnose, associadas, sistematizadas, ininterrompidas de maneira a formar uma trama contínua e como que um segundo eu, mas um eu latente, inconsciente, que contrasta estranhamente com o eu oficial do qual vós conheceis a amnésia profunda. (Charcot, citado em Cazeto, 2001, p. 294)

Em outra aula, Charcot vai afirmar que essa tendência à divisão da personalidade é comum a todas as histéricas (Cazeto, 2001). Essa ideia está presente também no trabalho de Binet, outro discípulo de Charcot, que declarava: "eu considero como suficientemente 
estabelecido o fato de que, de um modo geral, dois estados de consciência, ignorando-se mutuamente, podem coexistir no espírito de um sujeito histérico." (Binet, citado em Trillat, 1991, p.198). Outro que irá abordar o tema é Janet, a quem é confiado a missão de tratar Emma. Em sua tese intitulada L'automatisme psychologique, ele propõe a teoria de que a personalidade seria composta por duas instâncias: uma é responsável por conservar as organizações do passado; a outra tem a função de sintetizar e organizar os fenômenos presentes. Nos casos de histeria, entre outros, ocorreria um estreitamento do campo da consciência graças à diminuição da capacidade de síntese, permitindo, assim, que uma seconde conscience se manifestasse por meio de processos mentais inconscientes que passariam a determinar o comportamento do sujeito (Pereira, 2008).

A noção de divisão de consciência tem, no entanto, uma história anterior à de Charcot e seus discípulos e está intimamente ligada à prática da hipnose. Os magnetizadores do final do século XVIII e início do século XIX deparavam-se não só com os casos patológicos de dupla ou múltipla personalidade, como também com o surgimento de uma segunda consciência durante os transes hipnóticos. Foi por meio desse fenômeno que um dos pioneiros do mesmerismo, 0 marquês de Puységur, desenvolveu a noção de sonambulismo artificial: ao tentar praticar a cura magnética de Mesmer com um de seus criados, o jovem Victor Race, foi surpreendido pelo fato do camponês entrar em um estado diferente de consciência em que apresentava faculdades fora do comum, inclusive a capacidade de prever como se daria a própria cura. Puységur e seus discípulos, no entanto, encaravam os estados sonambúlicos, em que essa segunda consciência emergia, como um momento inteligente e criativo da subjetividade (Neubern, 2009).

Tal postura diferencia-se daquela adotada pelo pensamento clínico da segunda metade do século XIX, em que a hipnose e a divisão da consciência eram vistas como pertencentes unicamente à dimensão da patologia. Cazeto (2001) aponta que os trabalhos de Azam são fundamentais no estabelecimento dessa visão. Esse médico francês é considerado o introdutor do hipnotismo (como ele foi desenvolvido por Braid na Inglaterra) na França e marcou época com a investigação do caso de dupla personalidade de Félida X. A jovem costureira alternava, na visão de Azam, entre dois diferentes estados de consciência (havia, aparentemente, outros), sendo que um deles era caracterizado pela amnésia em relação ao que ela fazia quando estava sob a égide do segundo. A condição segunda era considerada um estado de total sonambulismo. A partir de Azam, observa Hacking, considerava-se que "era parte da natureza de uma portadora de dupla personalidade ser uma histérica. Era parte da sua natureza ser hipnotizável." (Hacking, 2000, p. 187) 


\section{Inconsciente Romântico}

Em um texto publicado no mesmo mês da Comunicação Preliminar, intitulado Um caso de cura pelo hipnotismo (2006d), Freud vai aproximar-se de uma noção de inconsciente que, apesar de manter sua afinidade com o modelo cognitivo e de divisão da consciência, será encarado como algo pertencente a todos. Nele, Freud esboça uma explicação etiológica da histeria em termos essencialmente psicológicos. As ideias que produzem os sintomas são qualificadas como antitéticas e expressam as dúvidas e conjecturas que se opõe às intenções ou expectativas conscientes das pessoas. No funcionamento normal, tais ideias são reprimidas ou inibidas, sendo dissociadas dos pensamentos e nem sequer notadas. Nas pessoas que estão sob domínio de uma neurose, no entanto, as ideias antitéticas ganham força, impedindo a realização das intenções e se sobrepondo às expectativas positivas sobre o que pode acontecer.

Freud, no entanto, vai tentar distinguir, de forma relutante, as diferentes maneiras em que age a ideia antitética na neurastenia e na histeria. No primeiro caso, haveria uma combinação com a ideia volitiva resultando num "único ato da consciência" e na consequente fraqueza da vontade. Já no segundo, o mecanismo se daria de forma inconsciente:

[Em primeiro lugar] em consonância com a tendência à dissociação da consciência (grifo do autor) na histeria, a ideia antitética aflitiva, que parece estar inibida, é afastada da associação com a intenção e continua a existir como ideia desconectada, muitas vezes inconscientemente para o próprio paciente. [Em segundo lugar] é extremamente característico da histeria que, quando chega o momento de se pôr em execução a intenção, a ideia antitética inibida consegue atualizar-se através da inervação do corpo, com a mesma facilidade com que o faz, em circunstâncias normais, uma ideia volitiva. A ideia antitética se estabelece, por assim dizer, como uma 'contra vontade', ao passo que o paciente, surpreso, apercebese de que tem uma vontade que é resoluta, porém impotente (Freud, 2006d, p. 164).

Nesse trecho, Freud respalda a noção de Charcot e de seus discípulos de que, na histeria, ocorre uma dissociação da consciência. Essa cisão acaba por revelar esse outro lugar psíquico em que são normalmente lançadas as ideias inconvenientes, mas que continuam a existir de forma inconsciente. Eis aqui um esboço do processo de recalcamento, e, também, de um inconsciente tópico, reservatório desse material abolido da consciência. Em outro trecho do texto, Freud vai traçar um 
retrato desse lugar, morada das ideias rechaçadas não só dos neuróticos, mas de todo ser humano:

Parece destituído de significação querer saber o que acontece às intenções inibidas em relação à vida ideativa normal. Poderíamos ser tentados a responder que elas simplesmente não existem. O estudo da histeria mostra que, não obstante, elas realmente (grifo do autor) existem, ou seja, que é mantida a modificação física a elas correspondente e que elas são armazenadas e levam a vida insuspeitada numa espécie de reino das sombras, até emergirem como maus espíritos e assumirem o controle do corpo, que, geralmente, está sob as ordens da predominante consciência do ego (Freud, 2006d, p. 169).

O texto já traz o esquema embrionário de um dualismo psíquico composto por um ego, lugar da consciência, e um inconsciente ainda não nomeado, que, no entanto, tem existência própria, apesar de seus conteúdos (ideias antitéticas) só virem à luz nos casos de neurose. Scandelari (2010) realça a ruptura das concepções de Freud expressas no texto em relação aos escritos precedentes:

Dessa forma, poderíamos ousar destacar, foi constituída a primeira teoria psíquica totalmente freudiana acerca da origem dos sintomas histéricos (...) havia, já aqui, uma concepção do campo psíquico relacionada ao inconsciente, que é inédita em sua lógica se compararmos às construções dos textos anteriores (Scandelari, 2010, p. 51).

Para descrever esse estranho lugar e os fenômenos a ele associados, Freud opta por utilizar imagens relacionadas aos casos de possessão demoníaca, misturada com termos estritamente psicológicos, como consciência do ego. Esse inconsciente não-nomeado tem aqui um caráter diabólico - intrincado, obscuro, inexplicável. Talvez por isso, essa será a única tentativa feita por Freud de descrevê-lo nos textos escritos ou publicados nos anos de 1892 e 1893 . O esforço parece não ter agradado ao autor, que não incluiu o texto em sua coletânea de trabalhos Escritos breves sobre a teoria das neuroses (Jones, 1959).

A referência aos casos de possessão não é casual: Charcot colecionava histórias desse tipo ocorridas na Idade Média e usava-as para provar a semelhança entre as manifestações histéricas daquela época e as de seu tempo (Freud, 2006e). No obituário escrito sobre Charcot, Freud observa que a teoria da divisão da consciência não passa de uma reedição em linguagem científica da concepção de que o demônio encarnado era a causa dos fenômenos histéricos. O 
inconsciente como "reino das sombras" é também uma imagem que remete à segunda tradição histórico-filosófica que Gödde (2010) aponta como necessária para compreender o conceito freudiano: a do romantismo. Entendido como uma reação ao Iluminismo do século XVIII, essa escola iniciada pelos filósofos alemães Hamman e Herder e pelo jovem Goethe, conheceu seu auge por meio da medicina romântica da primeira metade do século XIX e da filosofia da natureza. Entre as características principais do romantismo estão o culto ao irracional e ao individual, além do interesse pelo misticismo. Nesse contexto, 0 inconsciente surge como um conceito fundamental que liga o ser humano à natureza. Para os românticos, a exploração do lado "negro" da existência por meio da inspiração artística, dos sonhos ou do êxtase místico permitem ao homem obter um conhecimento, ainda que imperfeito, do universo (Ellenberger, 1970). É a essa concepção de um inconsciente como parte diabólica e transcendental de todos os seres que Freud faz referência nesse texto, em uma tentativa aparente de ir além das abordagens fisiológicas e clínicas desse objeto que irá capturar cada vez mais sua atenção na busca de explicações para o funcionamento psíquico humano.

\section{Conclusão}

Desde os seus primeiros escritos, já é possível identificar uma noção de inconsciente em Freud, que surge no âmbito de seu interesse pela histeria e pela hipnose. Assim como Charcot, ele é levado a distanciar-se da visão anatomopatológica para dar conta desses fenômenos clínicos. Esboça-se uma explicação psicológica para a histeria, ainda que submetida aos imperativos neurológicos. O mesmo ocorre com a noção de inconsciente: é ponto pacífico desde o início do pensamento freudiano de que há processos mentais que se dão fora do âmbito da consciência, mas que, mesmo assim, exercem influência sobre o corpo, sendo considerados, inclusive, fatores desencadeantes de sintomas histéricos. Essa noção de inconsciente se insere na tradição filosófica denominada cognitiva por Gödde (2010), cujos principais representantes são Leibniz, Herbart e Fechner.

Posteriormente, Freud passa a referir-se ao inconsciente como uma seconde conscience, fruto de um processo de dissociação patológico em que representações impossibilitadas de inserirem-se na consciência associam-se entre si, chegando a assumir o controle das ações dos doentes. Tal noção baseia-se nos trabalhos de Charcot sobre a histeria traumática, que também foi desenvolvida por outros discípulos seus, como Janet e Binet, e que buscava explicar a histeria como um fenômeno de divisão da personalidade. Nesse sentido, o 
discurso médico distancia-se daquele dos magnetizadores que, frente ao mesmo fenômeno, consideravam-no não como uma patologia, nos moldes estabelecidos por Azam, mas como a possibilidade de acesso a um inconsciente que tinha o poder de promover a própria cura. Ambos, no entanto, concebiam um modelo de psiquismo dividido.

Outra noção de inconsciente também se desdobra nos textos do período 1888-1893. Ela parte da consideração da existência de ideias antitéticas que são normalmente rechaçadas da consciência, mas que, na histeria, mesmo após serem dissociadas, conseguem agir no sentido de impedir a execução da vontade. Tais ideias possuem uma morada, um lugar para onde são lançadas e de onde, em alguns casos, retornam como assombrações. Freud refere-se aqui à existência de um inconsciente que se contrapõe a um ego, esboço de um dualismo psíquico que está ligado à ação do recalque. Para falar desse estranho lugar, Freud utiliza-se de imagens ("reino das sombras", "maus espíritos") que remetem aos casos de possessão da Idade Média, mas que também se inserem na tradição romântica que busca, por meio da exploração do irracional, do inconsciente, um conhecimento mais profundo e genuíno do universo e da vida.

Esses diferentes sentidos que a noção de inconsciente vai tomando nos trabalhos de Freud aqui analisados indicam a variedade de visões sobre esse objeto correntes no fim do século XIX, demonstrando, assim, a importância que a ideia de inconsciente havia assumido dentro do pensamento ocidental anterior à criação da psicanálise. Freud inicia suas investigações em torno da histeria e da hipnose apropriando-se dessas diferentes tradições, que vão lhe servir de base para a concepção futura de um conceito próprio de inconsciente, dentro do qual estarão reunidos algumas das características de cada um dos três modelos de inconsciente apontados. Isso demonstra a importância de um estudo aprofundado dos mesmos para a compreensão integral desse conceito metapsicológico fundamental da psicanálise.

\section{Referências}

Andersson, O. (2000). Freud precursor de Freud: estudos sobre a pré-história da psicanálise. São Paulo: Casa do Psicólogo.

Breuer, J. \& Freud, S. (2006a). Sobre o mecanismo psíquico dos fenômenos histéricos: Comunicação preliminar. In S. Freud Edição standard brasileira das obras psicológicas completas de Sigmund Freud, v. 2 (pp. 39-53). Rio de Janeiro: Imago. (Obra original publicada em 1893).

Cazeto, S. J. (2001). A constituição do inconsciente em práticas clínicas na França do século XIX. São Paulo: Escuta/Fapesp. 
Ellenberger, H. F. (1970). The discovery of the unconscious. New York: Basic Books.

Freud, S. (2006b) Histeria. In S. Freud Edição standard brasileira das obras psicológicas completas de Sigmund Freud, vol. 1 (pp. 7794). Rio de Janeiro: Imago. (Obra original publicada em 1888a).

Freud, S. (2006c) Prefácio à tradução de De la suggestion, de Bernheim. In S. Freud Edição standard brasileira das obras psicológicas completas de Sigmund Freud, v. 1 (pp. 111-121). Rio de Janeiro: Imago. (Obra original publicada em 1888b).

Freud, S. (2006d). Um caso de cura pelo hipnotismo. In S. Freud Edição standard brasileira das obras psicológicas completas de Sigmund Freud, v. 1 (pp. 159-170). Rio de Janeiro: Imago. (Obra original publicada em 1893).

Freud, S. (2006e). Charcot. In S. Freud Edição standard brasileira das obras psicológicas completas de Sigmund Freud, v. 3 (pp. 21-32). Rio de Janeiro: Imago. (Obra original publicada em 1893).

Fróes, H. \& Viana, T. C. (2013). As noções de inconsciente derivadas da teoria da defesa: primeiras elaborações freudianas. Tempo Psicanalítico, 45(2), 267-285.

Garcia-Roza, L. A. (2001). Introdução à metapsicologia freudiana (5a ed.). Rio de Janeiro: Jorge Zahar.

Gödde, G. (2010). Thinking the unconscious. New York: Cambridge University Press.

Hacking, I. (2000). Múltipla personalidade e as ciências da memória. Rio de Janeiro: José Olympio.

Jones, E. (1959). Vida y obra de Sigmund Freud, v. I. Buenos Aires: Editorial Nova.

Lacan, J. (2008). O seminário, livro 11: os quatro conceitos fundamentais da psicanálise. Rio de Janeiro: Zahar (Seminário ministrado em 1964).

Leader, D. (2010). Pé de página para Freud. Rio de Janeiro: BestSeller.

Neubern, M. (2009). Psicologia, hipnose \& subjetividade: revisitando a história. Belo Horizonte: Diamante.

Pereira, M. E. (2008). Pierre Janet e os atos psíquicos inconscientes revelados pelo automatismo psíquico das histéricas. Rev. latinoam. psicopatol. fundam., 11(2), 301-309.

Scandelari, B. (2010). A construção do psíquico em Freud. Revista Ad verbum, 5(2), 46-51.

Trillat, E. (1991). História da histeria. São Paulo: Escuta. (Obra original publicada em 1986). 


\section{Endereço para correspondência}

\section{Henrique Fróes}

Universidade de Brasília

Programa de Pós-Graduação em Metafísica

Campus Darcy Ribeiro, ICC Norte, CEP 70910-900, Brasîlia - DF, Brasil

Endereço eletrônico: henrique.froes@gmail.com

\section{Terezinha de Camargo Viana}

Universidade de Brasília

Instituto de Psicologia

Campus Darcy Ribeiro, ICC Sul, CEP 70910-900, Brasîlia - DF, Brasil

Endereço eletrônico: tcviana@unb.br

Recebido em: 26/04/2015

Aprovado em: 25/07/2017

\section{Notas}

* Mestrando do Programa de Pós-Graduação em Metafísica da UnB. Mestre em Psicologia Clínica e Cultura e Especialista em Teoria Psicanalítica, ambos pela UnB.

** Professora Titular da UnB, Instituto de Psicologia, Programa de Pós-graduação em Psicologia Clínica e Cultura. Coordenadora do Laboratório de Psicanálise e Subjetivação. 